\title{
CrimRxiv
}

\section{Profiling Persons Reported Missing from Hospitals versus Mental Health Facilities}

Lorna Ferguson ${ }^{1}$

${ }^{1}$ University of Western Ontario

Published on: Jan 19, 2022

DOI: $10.21428 / c b 6 a b 371 . e 683 f 553$

License: Creative Commons Attribution 4.0 International License (CC-BY 4.0). 


\begin{abstract}
:
Missing person reports from hospitals and mental health facilities are a significant issue with potential for harm to patients and the community, along with resource detriments for police. Research on missing persons seldom considers the type of location from where people go missing, which can be troublesome due to the increased chances for harm during an episode from hospitals and mental health facilities. When location type is studied, these often remarkably different places are frequently blended together in analyses and discussions. This conflation has implications for research and the development of effective police preventive responses. To begin to address this gap, this study uses descriptive analysis and logistic regression to examine the profiles of those reported missing from hospitals versus those reported missing from mental health units. For this, data are taken from a sample of 916 closed missing person cases reported to a Canadian municipal police service over five years. Results suggest there are significant differences in both the descriptive and predictive profile of individuals reported missing from these two location types, such as individuals with varying mental health and cognitive issues going missing from each place, respectively. Given the findings, the implications for research, policing, and risk management are discussed.
\end{abstract}

\title{
Keywords:
}

Missing Persons; Policing; Predictive Profiles; Risk Assessment

This is a pre-copyedited, author-produced version of an article accepted for publication in Policing \& Society, following peer review. The version of record, Profiling Persons Reported Missing from Hospitals versusMental Health Facilities. International Journal of Police Science and Management, 23(4), 372-384, is available online at: http://dx.doi.org/10.1177/14613557211021868. When citing, please cite the version of record.

\section{Introduction}

In 2019, the Centre for Addiction and Mental Health (CAMH) hospital in Toronto, Canada, initiated an external review of their policies and procedures after several patients disappeared from their care, producing various high-profile missing persons cases (Wilson 2019). These events resulted in the expression of strong concern around public safety, as well as garnered significant media attention, particularly because one 
of the individuals was found not criminally responsible (NCR) for the murder of his roommate (Wilson 2019). From this review, CAMH (2019) acknowledged that a critical area for improvement involves the collaboration between police and health sectors regarding the management and response to missing persons as "police sometimes lack the information they need to assess risk in [these] cases and locate persons in the community." Consequently, one of their immediate recommendations was to "identify a set of key indicators for CAMH and [police] to track, trend, evaluate, and improve performance on return of [missing] patients" (CAMH 2019). While the CAMH evaluation stems from one location and police service, issues over the capricious relationship between the police and health sectors, as well as missing incidents from hospitals, are discussed in a global context and prevail across several decades (Niskanen et al. 1972; Crammer 1984; Bowers et al. 2000; Hunt et al. 2010).

There is a considerable body of research on missing from health settings. However, few researchers have considered missing episodes from health settings from a policing perspective (Hayden and Shalev-Greene 2018). Such focus is vital to developing strategies to reduce and prevent missing incidents, as well as because of a duty of care, safeguarding, and risk of harm (Hayden and Shalev-Greene 2018). The current evidence base, therefore, mostly addresses people going missing from these locations through a lens that fails to account for all parties involved in handling missing person cases. Without empirical attention, police responses and case handling practices are constrained to anecdotal or otherwise internally shared working knowledge that has not been tested and/or found to be effective.

Another issue is that the current literature on missing events from health settings has, at times, blended location types together in analyses and discussions under the catchall categories of "institutional locations" or "hospitals," or has omitted the location type as a factor for consideration altogether. Consequently, the issue of missing reports from hospitals or mental health facilities is not depicted as a distinct issue affecting policing, but instead is viewed as a general problem related to institutional locations. Yet, medical literature shows that hospitals when compared with mental health settings have appreciable differences in their environments, facilities, and security and staff available (Cabarkapa et al. 2020), which may be more or less conducive to individuals go missing. Due to this lack of distinction, police response efforts are unable to prioritize according to the factors associated with missing cases from each place. Thus, there is a need to extend the current body of literature on the impact of place type on the profile of missing persons. Altogether, the array of issues and research gaps fashions a ubiquitous issue for police that warrants attention. 


\section{LITERATURE REVIEW}

It has been well-documented that the variety of definitions for 'missing person' adds unnecessary confusion and complexity to these cases (Taylor et al. 2019). Also, the terms absent without leave (AWOL), unauthorized leave, absconding, absconder, and escape/escapees are used to explain this phenomenon, particularly in clinical research (Taylor et al. 2019). These phrases can be retained under the term 'missing person' as they represent the same police report creation. The Royal Canadian Mounted Police (RCMP) (2015:16) conceptualization is used in this study, namely that: "Anyone reported to or by police as someone whose whereabouts are unknown, whatever the circumstances of the disappearance." According to the National Centre for Missing Persons and Unidentified Remains (NCMPUR), a database containing national figures on missing persons police reports, there were 73,184 missing cases in 2019 (Canada's Missing 2019). These figures have remained relatively consistent across the years, with some increases from 2015 to 2019 (Canada's Missing 2019).

Missing persons cases are complex as many factors contribute to these incidents, which can place demands on police and police resources. For example, there are numerous antecedents to someone going missing, such as marital breakdown, financial difficulties, suicidal ideation, and mental disabilities, among others (Biehal et al. 2003; Stevenson et al. 2013; Taylor et al. 2019). These various precursors to missing events can make it difficult for police to triage each case and effectively focus their response efforts. In relation to missing from hospitals and mental health units in particular, much of the literature has found that patients who go missing are often those with diagnosed or undiagnosed mental health issues (i.e., schizophrenia) (Muir-Cochrane et al. 2010), cognitive and physical disabilities, and drug/alcohol dependencies (author cite). Thus, police are often searching for and returning individuals that are in a variety of states and differing capacities. Concerning the reasons for missing episodes, those who are reported missing from health settings are cited as doing so because of boredom, lack of privacy, fear of other patients, feelings of confinement, isolation, lack of meaningful activities, confusion and misunderstandings, and many more (Emanuel et al. 2017). This means that there is not one or a few specific 'triggers' influencing missingness from these locations, nor is there always a clear antecedent, compelling police response to be acutely case-by-case. All in all, several mechanisms influence and contribute to these episodes. Responding unfailingly to such varying and complex cases, combined with the reduced human and financial resources, is a challenge for police. 
Missing person cases from health settings can also produce high social, economic, and emotional costs that have far-reaching implications for many sectors, communities, and families and friends (Muir-Cochrane et al. 2010). Focusing on policing implications, research from the U.K. and Australia highlight that, specific to hospitals and mental health settings, police are implicated in returning over one-third of persons missing from hospitals (Bowers et al. 1998; Muir-Cochrane and Mosel 2008; Meehan et al. 1999; Dickens and Campbell 2001; Bartholomew et al. 2009; Wilkie et al. 2014). In Canada, recent research advances that around $12 \%$ of all missing person cases reported to the police are initiated by hospitals and mental health units (author cite). The volume of cases originating from such locations accrues an estimated cost for policing of around $£ 879,060$ per year (Hayden and Shalev-Greene 2018; Shalev Greene and Pakes 2013), which is over $\$ 1,500,000$ CAD. On top of this, existing studies state that multiple missing reports are considerably more likely to occur from hospitals and mental health units than other locations (Hayden and Shalev-Greene 2018; Shalev Greene and Pakes 2013). This adds further resource pressures as police can be called to retrieve the same individuals on numerous occasions, who are then regarded as vulnerable because of their repeated high-risk behaviour (Shalev Greene and Pakes 2013).

Other potential implications for police, aside from economic costs, are that they can face severe adverse publicity and criticism if they have issues locating or fail to find missing people, especially persons regarded as vulnerable (e.g., children/youth) or high profile (Swanton and Wilson 1989; Taylor et al. 2019). Family of the missing from these locations have been documented as viewing police responses as insensitive, dismissive, and lacking urgency. When issues with missing person cases occur (i.e., unresolved, negative perceptions), police, as well as health services, can suffer from loss of public confidence, reputational damage, harmful media exposure, and legal liability (Clark 2012; Parr and Stevenson 2013; Bowers et al. 1999; Muir-Cochrane et al. 2011; Muir-Cochrane et al. 2013).

Given the above issues, Hayden and Shalev-Greene (2018) reports that research has determined that police consensus on their role in missing person reports from hospitals and mental health facilities is that the police should not be relied upon to act as a "24-hour social service." Recent research from the U.K. notes that clinical and psychological domains should be heavily involved in the resolution of these cases and should have more resources available proceeding a missing episode as they are optimal for advancing interventions (Taylor et al. 2019). Thus, both clinical researchers and police convey some consensus in that these events ought to be handled more so by 
health services. Still, police are, typically, the go-to service for these events, especially for emergency and urgent responses and those at high risk for suicide and harm to others (Emanuel et al. 2017). To note, in some specific situations and jurisdictions in Canada, an "Order for Return" is initiated to engage police assistance in retrieving a missing patient under the Mental Health Act (Emanuel et al. 2017), whereby the person may be under a specific treatment order, and so locating the individual becomes a matter for the police (CAMH 2019). Regardless, these cases represent a 'mission creep' in which major cuts to public services, welfare services, and charities, result in more calls to police and police doing much of the heavy lifting, rendering them a 24-hour response service to missing person calls from hospitals and mental health facilities (Garside 2015; Millie 2013; Hayden and Shalev-Greene 2018).

Turning to police responses to missing person cases more generally, each police service across Canada operates within a context that requires different approaches and responses due to a variety of elements, such as community and jurisdictional size and geographic locale (Pfeifer 2006). Thus, there are no standardized police practices across Canada for these cases, given that instituting a restricted set of responses for all services would ignore the individual challenges encountered by each agency. To handle each report on an individual basis, searches and investigations are often distributed into several in-the-moment produced tasks to be completed and reported on (Shalev Greene and Pakes 2013). Before responding to these cases, however, one relatively consistent police practice across Canada is the use of a risk assessment form. This involves a series of questions that identify the nature and urgency of the missing person case based on several 'risk factors' that have been established by either the province/territory or the police service itself. Hence, the included factors for assessing risk can vary from service to service and largely depend, again, on internal knowledge. Some of the factors outlined within risk assessment forms are, in no particular order: 1) age (e.g., very young), 2) weather and other physical conditions (e.g., terrain), 3) physical and mental capacity (e.g., Alzheimer's), 4) the circumstances surrounding the disappearance (e.g., dangerous), and/or 5) mental illness or suicidality (British Columbia 2018; Government of Ontario 2018).

Outcomes of these cases vary, with most people being located within 24 hours (Canada's Missing 2019) and few experiencing harm (National Crime Agency [NCA] 2019). Although, there is a strong link between missingness and severe injury to others and self from hospitals and mental health units. For example, Australian researchers report that there is a suicide rate of $20 \%$ for absconders, of which most use violent methods (e.g., drowning, hanging, etc.) (Shah and Gansvaran 2000). Investigators 
have also found that specific to these places, other harm and adverse events with a high likelihood of occurring are alcohol consumption, overdose death, self-neglect, aggression, violence, sexual assault, and medication non-compliance (Bowers et al. 2003; Carr 2006; Dickens and Campbell 2001; Pages et al. 1998; Tammelleo 1999). For missing reports from other locations, however, harm befalls anywhere from zero around six per cent of cases (NCA 2019; author cite).

The challenge then is for police to assess risk across missing person reports by prioritizing cases through a triaged response approach and risk assessment framework (Pfeifer 2006), especially from hospitals and mental health units due to the potential for harm. This tactic can involve a resource dilemma for police as failing to utilize the appropriate resources may result in serious injury to the missing person but deploying unnecessary and ineffective resources is a drain on frontline policing and will increase vulnerability in other vital policing areas. Research on developing a risk assessment framework based on evidence-informed profiles or contributing factors could greatly benefit police, decrease negative implications, attenuate resource demands, and reduce missing incidents. Accordingly, this study focuses on these two location types that are regarded as particularly problematic and challenging, given the associated high risk for harm and resource strains. Such focus from a policing perspective can assist in providing an actuarial approach to initiatives aimed at reducing the volume of missing person cases from hospitals and mental health facilities.

\section{THE CURRENT STUDY}

Identifying the profile of missing individuals and the conditions surrounding missing incidents from these locations would assist police in risk management efforts. Risk management is a vital tool often used in clinical domains to safeguard the welfare of the patient and community (Muir-Cochrane et al. 2011). To apply this to policing, risk management is a means to prioritize and triage police response, as well as search for and locate the missing more efficiently. Risk assessment is one such tool that assists with these goals. Additionally, as identified by the $\mathrm{CAMH}$, looking at predictive indicators can provide insights for better collaboration between the police and health sectors. One way to examine indicators for risk assessment and management purposes is by profiling missing person cases. This process involves revealing distinguishing features between the types of missing people, as well as the reasons behind the episodes, and offers predictions for who and what kinds of cases are more likely to go missing (Foy 2006). Therefore, the purpose of this article is to uncover the descriptive 
and predictive profiles of the missing from hospitals versus mental health facilities to assist with informing police risk assessment and fill in knowledge gaps.

\section{METHODS}

\section{Data}

To examine the phenomenon of going missing from hospitals versus mental health facilities, data were extracted by a crime analyst from the record management system (RMS) of a Canadian municipal police service. These data were stored and managed per the standards instituted by the Canadian Tri-Council Agencies and the authors University Research Ethics Board, from which approval was received to carry out this research. Files obtained consisted of all closed missing person reports generated over a five-year period (2014 to 2018), which included a total of 8,519 cases. From this, a separate data set was created containing only those individual records who were reported missing from either hospitals or mental health facilities, which was noted under 'Location Type' in the files. This reduced the sample down to a total of 2,173. Then, any reports were excluded if it could not be clarified (i.e., from the qualitative data in the 'Remarks' or 'Synopsis' sections) whether the person went missing from a hospital or a portion of the hospital that is regarded as a mental health setting. For example, "missing from 7th floor" and "msng - psych floor" were coded by the police service as 'hospital,' yet these comments represent psychiatric wards. The reason for this exclusion was to ensure that there was no overlap between the location types. Such distinctions are important in this study as the purpose is to examine differences in the profile of those who goes missing from each place comparatively. This elimination process resulted in a reduced sample of 1,051 closed missing cases that contained sufficiently detailed information for the analysis reported here. Lastly, due to a relatively small number of cases having missing data, listwise deletion was used on the included variables, whereby incidents were removed if there were any missing values. This process led to a final sample of 916 individual missing person files from these location types during the study period.

\section{Variables}

The 'Location Type' variable is used here to examine the profile of who goes missing from hospitals versus mental health facilities, which stems from the RMS-generated category and qualitative data sections. These places are coded as either hospital or mental health facility. Given that data quality is of concern when researching with police data (Cantor and Allison 2003; Duncan 2020), the coding was verified by cross- 
referencing the address of each case with the hospital and mental health facility addresses within the city in which this police service is situated. To note, all hospital and mental health facility addresses located in this municipality were referenced throughout these data, indicating that the sample is representative of this city. As a final accuracy check, police officers working on the Search and Rescue (SAR) Team from this service also reviewed and verified the addresses and coding. This final process did not result in any exclusions or adjustments as there were no disagreements regarding the coding.

For missing person characteristics, the following demographic predictors were included: race, age group, and gender. For health information, any documented healthrelated concerns, issues, or statements throughout the 'Remarks' and 'Synopsis' segments of the data files were coded, as well as any pre-existing, RMS-generated variables. Lastly, for incident characteristics, probable cause, history of going missing, and the assigned urgency level were coded.

Concerning the demographic characteristics, the missing person's police-identified race/ethnicity was coded as White, Indigenous, Black, Asian, and Other. This latter group was created by collapsing the categories of Middle Eastern, East Indian, and Other into one variable due to low cell counts. A dummy variable for gender was created, where $0=$ male and $1=$ female. One limitation of these data is that a person's exact age is not mentioned, so this is not known for each missing individual. Instead, their age was reported as a range. For adults (aged 22 and above), the age groups were coded as they were categorized within the RMS data: 22-29 years, 30-49 years, 50-65 years, and over 65 years. However, for youth, adjustments were made to the RMS-generated groupings. The seven original categories (0-3 years, 4-5 years, 6-8 years, 9-11 years, 12-13 years, 14-15 years, and 16-17 years) were collapsed into one: 0-17 years. This occurred as there were very few missing reports within this age range, so including the pre-existing categories left too small of a sample size to provide stable and/or reliable results. The remaining included age group is 18-21 years.

Health information was coded according to the following RMS-generated classifications: drug/alcohol dependency, medical dependency, mental disability/senile, mental illness/possibly suicidal, and other/none known. Any qualitative data available under the free text sections of the files were also coded according to these categories (if they were not coded already), such as "is a known drug abuser" being coded as drug/alcohol dependency or "kidney disease - reliant on meds" as medical dependency. The 'other' RMS category was collapsed into 'none known' to create one grouping as 
there were no data files that included information on what 'other' entails. Given that it is unclear what 'other' represents, merging these two categories is necessary to ensure there are no ambiguities in what these cases include or exemplify.

Lastly, incident characteristics are the types of cases in this data set and involve the categories generated within the RMS. These contain probable cause explanations, which are the reasons police noted as why the person was reported missing: runaway, wandered off/lost, and other (i.e., "missed curfew"). History is comprised of no previous history, repeat, and habitual/chronic, which was assigned to the individual by the police service based on their knowledge of each case and access to any other occurrence reports. For context, 'repeat' missing person cases are commonly files with one to three previous missing reports, whereas 'habitual/chronic' reports are those that have a substantial number of prior missing episodes (i.e., more than three) and so are the biggest drivers of police missing person service calls $\underline{1}$. Finally, urgency level involves the following police-assigned groups: non-emergency, urgent, and emergency. These categories are assigned based upon police risk assessment, and are hierarchized and steer police response efforts. 'Emergency' cases represent the highest risk $\underline{2}$ and so demand the greatest amount of attention and police resources, 'urgent' files represent a moderate level of risk and so generate a fair amount of attention and police resources, and, lastly, 'non-emergency' reports often call for the least police resources.

\section{Models}

Logistic regression is used to analyze the profile of missing persons from hospitals in comparison to mental health facilities. The use of this model was selected as, given that the dependent variable in the analysis is binary (Location Type), the use of a linear probability model violates standard OLS assumptions. For a missing person $i$, the full model estimating the profile of missing persons from hospitals versus mental health units is:

$\log \frac{\pi(\text { missing from hospital })_{i}}{1-\pi(\text { missing from hospitals })_{i}}=\beta_{0}+\beta \mathbf{x}_{i}^{\prime}+\beta \mathbf{z}^{\prime}{ }_{i}+\varepsilon_{i}$,

where $\beta \mathbf{x}^{\prime}{ }_{\mathbf{i}}$ represents the set missing person characteristics (i.e., demographics), $\beta \mathbf{z}^{\prime}{ }_{\mathbf{i}}$ signifies the set of incident variables (i.e., case characteristics), and $\varepsilon_{i}$ captures residual variation. Below, the logit model provides estimates on the whole sample with hospital as the base category. This allows for direct comparisons between the two location types for the profiling of missing persons. 


\section{RESULTS}

\section{Descriptive Profile}

Table 1 presents a descriptive overview of the included covariates. Beginning with the explanatory variable, the number of reports from hospitals versus mental health facilities is roughly equal, with hospitals marginally producing more reports from 2014 to 2018 ( $\mathrm{n}=464 ; 50.4 \%$ ). Turning to the demographic variables, those identified as White constitute the most significant amount of reports across the years $(n=720$; $78.6 \%$ ), with $55.6 \%$ of reports including this group originating from hospitals. The closest represented group to White is Indigenous, who comprise 9.7\% of the total sample. Many cases are noted as male $(\mathrm{n}=568 ; 64.0 \%)$, of which both hospitals and mental health facilities initiated an almost equal number of reports. Lastly, those between the ages of 30-49 years comprise a significant majority ( $\mathrm{n}=378 ; 41.3 \%$ ) of these reports from both hospitals $(\mathrm{n}=164 ; 43.4 \%)$ and mental health units $(\mathrm{n}=214$; $56.6 \%)$. The next largest age category is $22-29$ years $(\mathrm{n}=297 ; 32.4 \%)$, which account for $53.2 \%(n=158)$ of the cases generated from hospitals and $46.8 \%(n=139)$ from mental health facilities.

Regarding the health covariates, those reported as having a mental disability and/or as senile, such as severe schizophrenia or dementia, account for a majority of cases from mental health facilities ( $\mathrm{n}=230 ; 56.7 \%$ ), whereas those noted as possibly suicidal or mentally ill, such as depression or bipolar disorder, comprise most cases from hospitals $(\mathrm{n}=188 ; 64.8 \%)$. Generally, those with a mental disability and/or senility account for more missing person reports than any other documented health characteristic $(\mathrm{n}=$ 406; 44.3\%). This could be explained by the growing aging population in Canada, resulting in several adults with cognitive impairments (author cite), or might represent a high number of people with mental disorders at such settings.

Lastly, for incident covariates, 'runaway' is cited as the reason one went missing substantially more than any other probable causes $(n=590 ; 64.4 \%)$. Specifically, $54.2 \%(n=320)$ of cases from hospitals and $45.8 \%(n=270)$ from mental health facilities involve runaways. This finding is notable as those classified as running away are documented in the existing literature as voluntarily going missing and often impulsively decide to leave (Payne 1995; Biehal et al. 2003; Taylor et al. 2019). However, it is not clear from these data whether the missing episodes are the result of intentionality, accident, disorientation, or rebellion, among other potential reasons. Turning to the number of cases across the total sample, most individuals were reported as repeatedly going missing $(n=337 ; 36.8 \%)$; however, differences can be 
seen across the location types. Those who go missing from hospitals often have no history of doing so ( $\mathrm{n}=179 ; 68.6 \%)$; whereas those classified as habitual/chronic account for most of the reports from mental health facilities ( $\mathrm{n}=200 ; 62.9 \%$ ). This shows that those missing from hospitals generally do so only one time, but cases from mental health facilities go missing several times.

Table 1. Descriptive Overview of Persons Reported Missing from Hospitals and Mental Health Facilities ( $\mathbf{N}=916)$

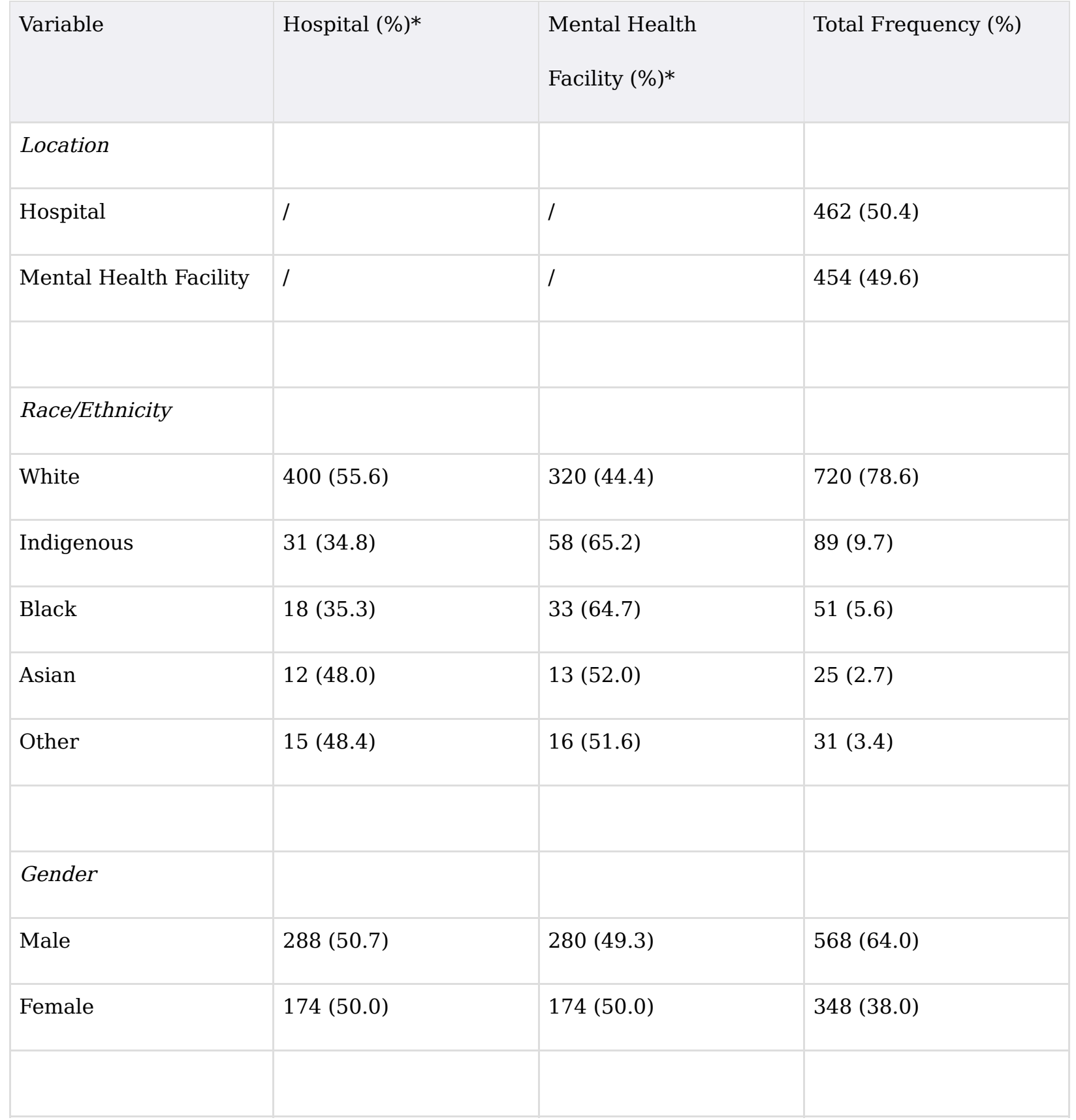




\begin{tabular}{|c|c|c|c|}
\hline \multicolumn{4}{|l|}{ Age Group } \\
\hline 0-17 Years & $20(80.0)$ & $5(20.0)$ & $25(2.7)$ \\
\hline 18-21 Years & $49(84.5)$ & $9(15.5)$ & $58(6.3)$ \\
\hline 22-29 Years & $158(53.2)$ & $139(46.8)$ & $297(32.4)$ \\
\hline 30-49 Years & $164(43.4)$ & $214(56.6)$ & $378(41.3)$ \\
\hline 50-65 Years & $56(48.3)$ & $60(51.7)$ & $116(12.7)$ \\
\hline Over 65 Years & $21(50.0)$ & $21(50.0)$ & $42(4.6)$ \\
\hline \multicolumn{4}{|l|}{ Health Information } \\
\hline $\begin{array}{l}\text { Mental } \\
\text { Disability/Senile }\end{array}$ & $176(43.3)$ & $230(56.7)$ & $406(44.3)$ \\
\hline Mental Illness/Suicidal & $188(64.8)$ & $102(35.2)$ & $290(31.7)$ \\
\hline $\begin{array}{l}\text { Drug/Alcohol } \\
\text { Dependent }\end{array}$ & $60(39.7)$ & $91(60.3)$ & $151(16.5)$ \\
\hline Other/None Known & $43(62.3)$ & $26(37.7)$ & $69(7.5)$ \\
\hline \multicolumn{4}{|l|}{ Probable Cause } \\
\hline Runaway & $320(54.2)$ & $270(45.8)$ & $590(64.4)$ \\
\hline Wandered Off/Lost & $73(44.0)$ & $93(56.0)$ & $166(18.1)$ \\
\hline Other & 75 (46.9) & $85(53.1)$ & $160(17.5)$ \\
\hline \multicolumn{4}{|l|}{ History } \\
\hline Repeat & $170(50.4)$ & $167(49.6)$ & $337(36.8)$ \\
\hline
\end{tabular}




\begin{tabular}{|l|l|l|l|}
\hline Habitual/Chronic & $118(37.1)$ & $200(62.9)$ & $318(34.7)$ \\
\hline No Previous History & $179(68.6)$ & $82(31.4)$ & $261(28.5)$ \\
\hline Urgency Level & $331(47.7)$ & $363(52.3)$ & \\
\hline Non-Emergency & $46(63.9)$ & $26(36.1)$ & $694(75.8)$ \\
\hline Emergency & $100(66.7)$ & $50(33.3)$ & $150(16.4)$ \\
\hline Urgent & & & $729)$ \\
\hline
\end{tabular}

*The percentages for these columns are calculated using the total frequency for each group.

Overall, as shown in Figure 1, the descriptive profile of those reported missing from hospitals are White, males, aged 30-49 years, with a mental illness and/or are possibly suicidal, runaways, either repeat missing persons or no history of 'going missing,' and non-emergencies. For mental health facilities, the profile is somewhat similar, where the common cases are White, males, aged 30-49 years, runaways, and nonemergencies, but instead have a mental disability or senility and are habitual/chronic. These profiles are explored more in the upcoming section. 
Figure 1. Descriptive Profile of The Missing from Hospitals Versus Mental Health Facilities
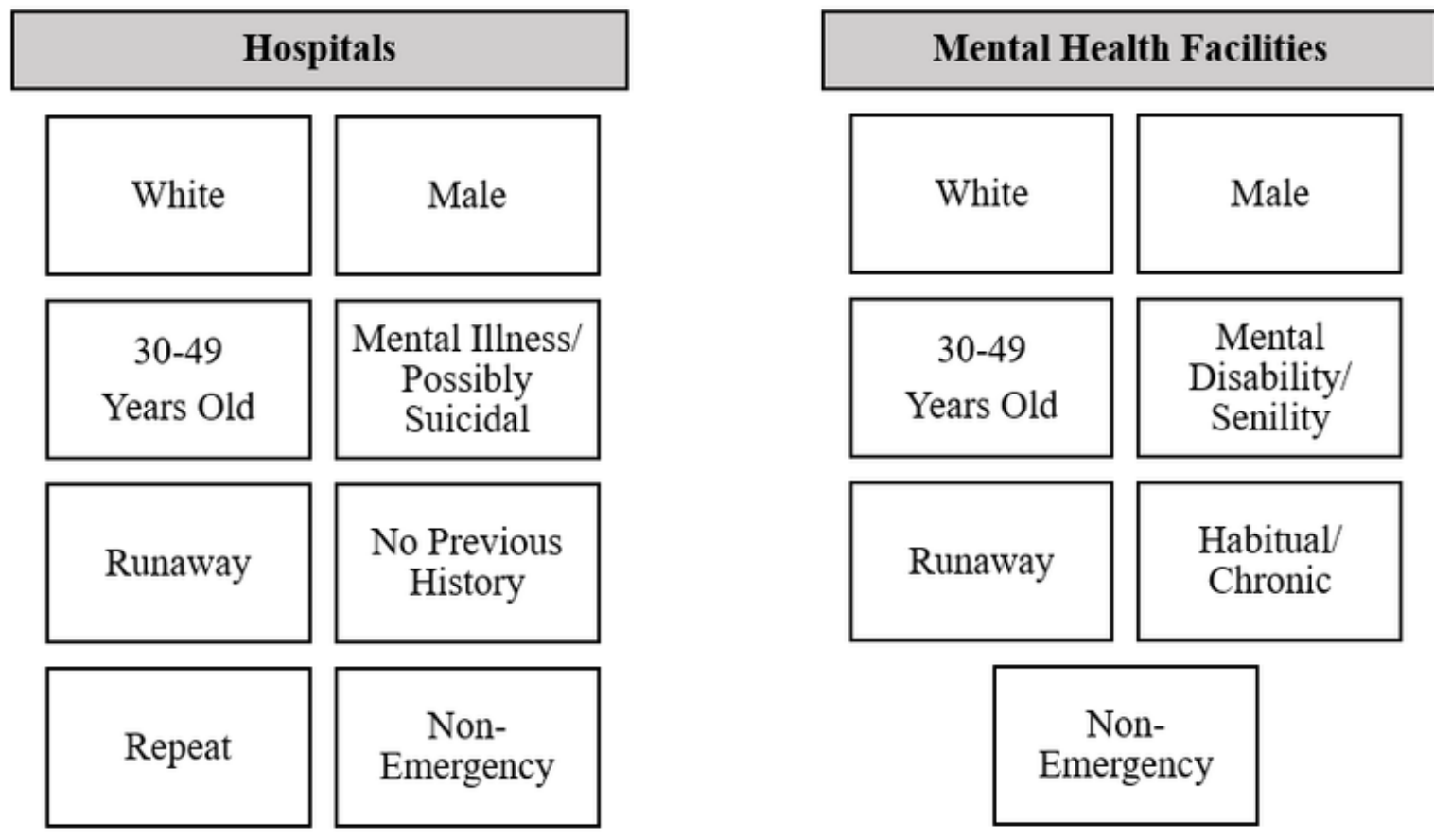

\section{Predictive Profile}

Table 2 displays the estimates of the logit model predicting the profile of missing persons from mental health facilities with hospital as the base category.

Table 2. Odds Ratios from Logistic Regression Model Predicting Profile of Missing Persons from Hospitals Versus Mental Health Facilities

\section{Race/Ethnicity (White)}

Indigenous

$2.201 * *$

(0.589)

Black

$$
2.934^{* * *}
$$

$(0.981)$ 


\begin{tabular}{|c|c|}
\hline & $(0.601)$ \\
\hline \multirow[t]{2}{*}{ Other } & $2.015 t$ \\
\hline & $(0.837)$ \\
\hline \multirow[t]{2}{*}{ Female } & $0.939 t$ \\
\hline & $(0.149)$ \\
\hline \multirow[t]{2}{*}{ Age (Years) } & $1.467 * * *$ \\
\hline & $(0.113)$ \\
\hline \multicolumn{2}{|c|}{ Health Information (Other/None Known) } \\
\hline \multirow[t]{2}{*}{ Drug/Alcohol Dependency } & $2.607^{* *}$ \\
\hline & $(0.836)$ \\
\hline \multirow[t]{2}{*}{ Mental Disability/Senile } & $2.171 * *$ \\
\hline & $(0.619)$ \\
\hline \multirow[t]{2}{*}{ Mental Illness/Possibly Suicidal } & $1.203^{*}$ \\
\hline & $(0.357)$ \\
\hline \multicolumn{2}{|l|}{ Probable Cause (Other) } \\
\hline \multirow[t]{2}{*}{ Runaway } & $0.614^{* *}$ \\
\hline & $(0.121)$ \\
\hline Wandered Off/Lost & 1.063 \\
\hline
\end{tabular}




\begin{tabular}{|l|l|}
\hline & $(0.259)$ \\
\hline History (No Previous History) & \\
\hline Repeat & $2.318^{* * *}$ \\
\hline Habitual/Chronic & $(0.437)$ \\
\hline Assigned Urgency (Non-Emergency) & $3.880^{* * *}$ \\
\hline Emergency & $(0.775)$ \\
\hline Urgent & $0.537 *$ \\
\hline & $(0.152)$ \\
\hline & $0.475^{* * *}$ \\
\hline & \\
\hline
\end{tabular}

Standard errors are in parentheses below parameter estimates.

The base category is 'Hospital' as the location.

$\dagger p<.10 ; * p<.05 ; * * p<.01 ; * * * p<.001$.

Weighted estimates by $95 \%$ CIs.

Noticeably, the findings reveal distinctive profiles of missing cases from hospitals relative to mental health facilities. The predictive profile of missing individuals from mental health facilities when compared to hospitals is significantly more likely to be males, older, and those noted as Indigenous, Black, or other race/ethnicity. To expand on this, female gender emerged marginally significant, wherein they are 0.939 times less likely to go missing from mental health facilities relative to hospitals. The older an individual is, the higher the odds that they will go missing from mental health facilities in comparison to hospitals (1.467 times or $186.8 \%$ ). Lastly, those classified as 
Indigenous (2.201 times or $120.1 \%)$, Black (2.934 times or $193.4 \%)$, and other race/ethnicity (2.015 times or $101.5 \%$ ) are significantly more likely to go missing from these facilities compared to hospitals.

Concerning health information, every documented health concern significantly increased the odds of an individual going missing from a mental health setting compared to hospitals. For example, those reported as drug/alcohol dependent emerged as almost three times more likely to go missing from mental health facilities. The other health covariates also emerged as significant and positively associated with mental health facilities, whereby those noted as having a mental disability/senile (2.171 times or $117.1 \%$ ) and 'mental illness/possibly suicidal' (1.203 times or 20.3\%) are more likely to go missing from mental health facilities when compared to hospitals.

Lastly, for case characteristics, repeat and habitual/chronic cases are more likely to go missing from mental health facilities. Notably, those cases classified by police at the highest level of risk (urgent) are significantly less likely to occur from mental health settings instead of hospitals. Cases from mental health facilities are not significantly more likely to be classified as anything other than non-emergency. As well, cases from mental health facilities are almost four times more likely to involve habitual/chronic (3.880 times) and are over two times more likely to be repeat (2.318 times). Thus, the profile for mental health facilities is that of non-emergency cases that involve people who have been reported as missing at least one time in the past. This finding may represent that those who go missing several times are perceived to be less of an emergency (by the responding officers, not a risk assessment) than those who go missing for the first time, as the first missing report is regarded as an out-of-character behaviour.

Synthesizing the above, Figure 2 offers a graphic display of profiles for mental health settings. As shown, Indigenous, Black, other race groups, older adults, and with a previous history of going missing, drug/alcohol dependencies, mental disability/senility, and mental illness/possibly suicidal embody the profile of missing persons from mental health facilities when compared to hospitals. In contrast, this means that profile from hospitals when compared to mental health facilities is White, females, and those who have the capacity to run away from the situation or environment. Thus, different profiles of people and cases go missing from each location type. This highlights that without isolating hospitals from mental health settings in analyses and discussions, results may not be indicative of the reality of missing persons cases, which can 
misinform police procedures and practices and affect the quality and applicability of research.

Figure 2. Graphical Display of the Odds Ratios from Hospitals vs. Mental Health Facilities

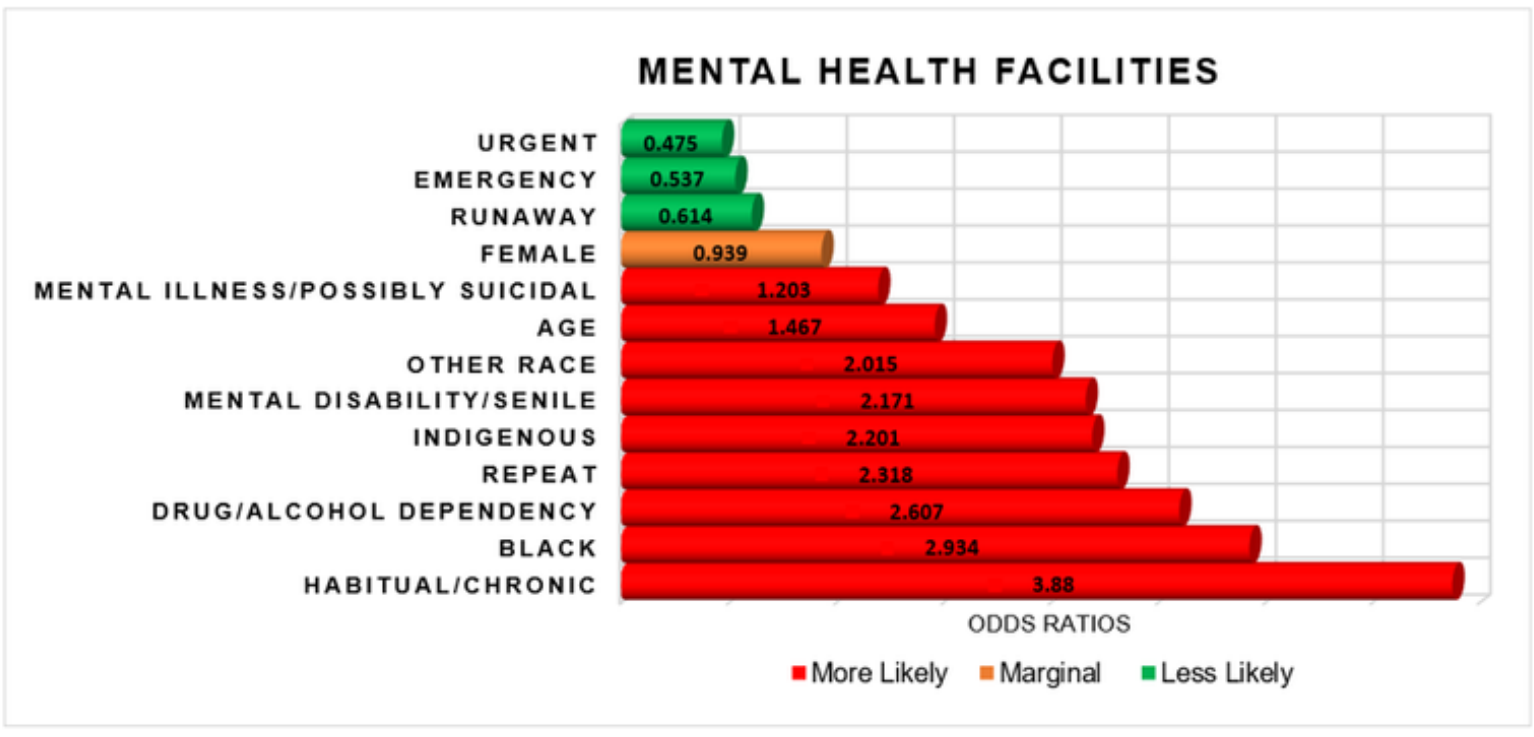

\section{DISCUSSION}

This study investigated the common profile of people reported missing from hospitals versus mental health facilities, as well as examined the missing person and case characteristics associated with each incident to generate profiles of missing persons. Based on the findings, it can be said that profiling has potential in policing as distinctive predictive profiles emerged based on the type of place, which has implications for police procedures and practices, as well as for future research. Risk management approaches should consider the indicators found to be associated with missing person cases from each location type, which could be trialled to reduce the incidence of missingness, and, ultimately, attenuate police resource demands. Altogether, the insights provided have the potential to help police direct their efforts toward areas that require discriminating, pertinent, and instructive strategies, such as missing reports from these location types with increased likelihood of harm. While the findings offer an initial understanding of missing person cases from these locations in Canada, several key contributions are provided that extend the existing literature.

First, there are distinguished descriptive and predictive profiles of missing person cases from each location type. This finding suggests that managing and assessing risk 
under the categories of "institutional location" or "hospital" does not suffice. The importance of police isolating these places within their data gathering is evident throughout this study, given that it can be crucial to calculations of risk. For example, police officers, when fulfilling a risk assessment form for a missing person case from a "hospital," could gather additional data on whether the individual is a hospital patient or patient in a mental health setting. This would prepare a better-informed risk assessment that assists in determining an appropriate level of police response, as well as directing such responses (i.e., targeted deployment of resources) (Bonny et al. 2016; Biehal et al. 2003). Previous research examining locations and missing people have similarly stated the same, but also questioned the extent to which the place one goes missing from can be weighted, given that there is a paucity of research on this matter (Hayden and Goodship 2015). Nonetheless, this study delivers strong support for approaching risk assessment differently in ways that could induce efficient responses to missing person reports from these locations and improve the use of police resources. Overall, examining location types is a fruitful avenue for further exploration as risk is shown to differ depending on the place in which one is reported missing.

The next contribution is the common profiles of those reported missing from hospitals compared to mental health facilities in Canada. For hospitals, the profile consists of middle-aged, White, males, who have some mental illness and/or are possibly suicidal. These cases are also typically runaways, repeat or first-time, and non-emergencies. Whereas for mental health settings, the profile is also that of middle-aged, White, males, who are reported as running away and non-emergency cases, but instead are living with a mental disability or senility and are habitual/chronic. The demographic profile of cases from these locations is mostly consistent with the extant body of literature in that men when compared to women (Farragher et al. 1996; Quinsey et al. 1997; Bowers et al. 1999; Bowers et al. 2000; Meehan et al. 1999), and White when compared to other race/ethnicity groups (Hayden and Shalev-Greene 2018; Brook et al. 1999) are responsible for more missing events from these locations. Though, future research would benefit from expanding the examined data to explore race and missingness in a Canadian context, given that many recent reviews and reports highlight that Indigenous peoples, specifically women, are especially at-risk for going missing and experiencing harm during these episodes (e.g., Cohen et al. 2008; Cohen et al. 2009).

Interestingly, older adults constituted the descriptive profile of the missing from both place types, which contrasts with existing scholarship indicating that young individuals mostly go missing from these places (Meehan et al. 1999; Muir-Cochrane et al. 2010; 
Bowers et al. 1998; Bowers et al. 2003). However, specific to this finding, researchers explain that this may be more to do with patient admittance leading to an overrepresentation of young individuals in patient profiles (Meehan et al. 1999; MuirCochrane et al. 2010). In this study, the profile of missing persons from each location consists mostly of middle-aged individuals. Explanations for this finding are not available from this study; however, this may similarly indicate that older adults are the typical profile of persons admitted to hospitals and mental health facilities instead of the pattern of missing persons from these locations. Future research on patient admittance compared to missing patient profiles in Canada would be useful for providing clarity on this variation.

The common profiles of health concerns and case characteristics from each place type reveal some interesting distinctions. The most striking difference was in the history of missingness from hospitals versus mental health facilities, whereby cases from hospitals typically have no previous history of going missing. Yet, for mental health facilities, individuals commonly go missing multiple times as they are mostly habitual/chronic cases. This represents a reason for concern in the duty of care and protection practices of mental health facilities and a significant issue for police due to resource implications and increased chances of exposure to harm (Hayden and ShalevGreene 2018; Muir-Cochrane et al. 2010). Explicitly, risks are particularly critical when people go repeatedly missing (Hayden and Shalev-Greene 2018). The high incidence of multiple missing persons cases from mental health facilities is a sign that there may be something wrong with where they are or the situation they are in, or institutional issues are contributing to these incidents (i.e., security, staff, institutional abuse, etc.) (Rees and Lees 2005; Hayden and Goodship 2015). This finding is further notable because of the most significant probable cause explanation being running away. These patterns are mirrored across the literature on missing events from these places, and many researchers have called for further investigation into why many patients go missing repeatedly and run away from mental health settings (Rees and Lees 2005; Hayden and Goodship 2015; Muir-Cochrane et al. 2010; Hayden and Shalev-Greene 2018).

Turning to health concerns, the common profile of missing persons highlights that most patients missing from mental health settings have mental disabilities and/or senility, followed by mental illnesses and are possibly suicidal. For hospitals, most cases have mental illnesses or are suicidal, followed by mental disability or senility. Taken together, cases from hospitals and mental health facilities can be particularly challenging given the variety of capacities and states people may be in when police are 
searching for and locating them, compounded with the high incidence of repeat missing reports and running away as reasoning for the episodes. These findings strongly emphasize the need for research on how to lessen these occurrences, generate evidence-informed risk assessment, and foster collaboration between police and health sectors for each location type independently.

Lastly, this study offers predictive profiles concerning who goes missing from each location and the subsequent risk for exposure to harm, as well as the case circumstances. These predictive profiles markedly show that different people and cases are more at risk of harm and are more likely to go missing from each place. The strongest message from these findings is threefold. First, there are more factors associated with risk of harm and a higher likelihood of missingness from mental health facilities when compared to hospitals. This highlights that missing person cases from mental health facilities require a particular focus from both police and health sectors, especially in terms of establishing risk assessment and knowledge sharing, to reduce episodes and lessen the resources attributed to these cases. That is, efforts are required to strengthen police and mental health facility partnerships, joint risk assessments, the revision of procedures and protocols, and the sharing of knowledge and support. Second, most of these high-risk factors involved health-related issues, which calls into question whether the health services may be better positioned to handle these cases than police (i.e., trained, knowledgeable staff).

Lastly, there are several patient-specific and setting-specific differences in the predictive profiles, which could serve as choice points for interventions to reduce the incidence of missing person reports from these locations. These variables represent areas in which police could target more resources, such as front-loading resources, when a missing call arrives involving any factors established as increasing risk from each place. Directing resources to high-risk cases would moderate issues with balancing police resources without creating vulnerabilities for policing in other areas, as this is a strategic allocation effort. That is, these predictive profiles provide indicators that can be targeted in police decision-making, responses, and procedures. Altogether, the findings concede that patterns within missing person's data can be pinpointed and that, by including data on location types in police risk management efforts, the generation of precise categorization and predictive criteria to attenuate police demands for these cases is highly probable (Foy 2006).

What do these findings mean for police? First, research on persons reported missing from hospitals and mental health facilities specifically from a policing perspective for 
assessing possible risk is one such area that should be focused upon for the future development of police procedures and practices. Granted that this study is a first look into distinctions between these cases, to extend the objective base would serve to guide police practices with empirical research, instead of anecdotal or internally shared working knowledge. Therefore, this study is one step towards developing more robust methods for classifying possible risk from these places as it offers an actuarial approach that can inform strategies in the missing persons and policing arena (Kiernan and Henderson 2002; Foy 2006). Second, risk assessment based on predictive variables from each location type can help advise the search and investigation process, determine the resources allocated, and manage each case (e.g., informing investigative enquires, avenues for search and rescue efforts, determination of risk) (College of Policing 2016; Hayden and Shalev-Greene 2018; Emanuel et al. 2017; Foy 2006). The factors found in this study rendering an individual particularly at high risk of going missing and harm from each location should be considered in future police risk management and response efforts.

Third, the call for the advancement of evidence-informed risk assessment for cases from each location provides an opportunity for police to collaborate with health representatives and other key stakeholders. Given that working closely with the health sectors would allow for the development of knowledge and support on these cases (CAMH 2019), risk assessment construction is one such area that would assist in rapport and relationship building among both domains. Fourth, due to the complexities associated with these cases and the potential harm that can result from missing episodes, police response to cases originating from hospitals and mental health facilities should be prioritized and triaged particularly according to the risk profiles consisting of the individuals most at-risk for going missing and harm from each place. Lastly, this study indicates that police response and risk assessment should be adjusted to not only consider the factors established in the body of literature as placing one at higher risk for missingness, but also could gather information on the location from which the individual was reported missing and should signify place type as an indicator for potential risk.

\section{Limitations}

There are some limitations to the current study that must be addressed. First, these data do not allow for conclusions regarding causality in any type of meaningful way. To meet the criteria for causality, cross-sectional research designs are not suitable, and temporal precedence regarding the covariates must be established before including 
them in the analyses (Kraemer et al. 1997). Given that this is likely to be a prevailing issue with missing persons research, future research would benefit from establishing an evidence base surrounding the phenomenon of going missing from hospitals and mental health settings in Canada from a variety of disciplines and perspectives to form critical patterns. Next, listwise deletion was used to exclude any missing values, which resulted in these cases not being included in the analyses.

Also, this data set did not record distinctions between patients who had been detained by police at hospitals or mental health facilities under the Mental Health Act, which means that information is not available on whether the patient was voluntary or involuntary, nor did it include details on if the person left the hospital with or without formal approval. This limitation was unavoidable given the use of police data. Absence of information on this makes it impossible to offer comparisons between these categories. Future research would benefit from separating the types of patients in analysis in a Canadian context, which could occur with the use of institutional data or analyses of qualitative police data. Finally, while the present study examined closed missing person reports over several years from hospitals and mental health units, it would be useful for future work to extend this research by investigating these location types across other police services and additional years. That is, the use of crosssectional data from one police service in this study means that the findings may not be generalizable to other locations across Canada or globally. Regardless, the results show patterns that do not appear as due to chance alone as they reflect similar findings in previous literature.

\section{CONCLUSION}

The present study contributes to an understanding of missing person variables associated with the phenomenon of going missing from hospitals compared to mental health facilities. In doing so, factors of which police and health sectors should be particularly aware of in risk assessment and response planning become apparent. Findings highlight that missing events from each location type is a problem of ample prevalence to warrant greater attention and isolation in police data gathering and future research efforts. This study has demonstrated that there are distinctions in the common and predictive profiles of the missing from hospitals in comparison to mental health facilities, showing that examining the influence of location types of missingness is worthy of further investigation. This work adds to the literature documenting missing persons, particularly in Canada, and offers other factors for consideration in the efforts to profile missing persons. 


\section{References}

Bartholomew, D., Duffy, D., \& Figgins, N. 2009. Strategies to reduce missing patients: A practical workbook. London: National Mental Health Development Unit. Available from https://www.scribd.com/document/36352199/A-Strategy-to-Reduce-Missing= Patients-a-Practical-Workbook.

Biehal, N., Mitchell, F., \& Wade, J. 2003. Lost from view: Missing persons in the U.K. Available from: http://www.york.ac.uk/inst/spru/pubs/pdf/MissingPersons.pdf.

Bonny, E., Almond, L., \& Woolnough, P. 2016. Adult missing persons: Can an investigative framework be generated using behavioural themes? Journal of Investigative Psychology and Offender Profiling, 13, 296-312.

Bowers, L. 2014. Safewards: a new model of conflict and containment on psychiatric wards. Journal of Psychiatric and Mental Health Nursing, 21(6), 499-508.

Bowers, L., Simpson, A., \& Alexander, J. 2005. Real world application of an intervention to reduce absconding. Journal of Psychiatric and Mental Health Nursing, 12(5), 598602.

Bowers, L., Simpson, A., \& Alexander, J. 2005. Real world application of an intervention to reduce absconding. Journal of Psychiatric and Mental Health Nursing, 12(5), 598602 .

Bowers L., Jarrett, M., Clark, N., Kiyimba, F., \& McFarlane, L. 2000. Determinants of absconding by patients on acute psychiatric wards. Journal of Advanced Nursing, 32, 644-649.

Bowers L., Jarrett, M., Clark, N., Kiyimba, F., \& McFarlane, L. 1999. Absconding: Outcome and Risk. Journal of Psychiatric and Mental Health Nursing, 6, 213-218.

Bowers, L., Jarrett, M., \& Clark, N. 1998. Absconding: a literature review. J Psychiatr Ment Health Nurs, 5(5), 343-53.

British Columbia. 2018. Provincial Policing Standards. Available from: https://www2.gov.bc.ca/assets/gov/law-crime-and-justice/criminaljustice/police/standards/5-1-2-risk-assessment.pdf.

Brook, R., Dolan, M., \& Coorey, P. 1999. Absconding of patients detained in an English special hospital. The Journal of Forensic Psychiatry, 10(1), 46-58. 
Buckley, M. 2012. Police and practices in the investigation of missing persons. Available from: http://www.missingwomeninquiry.ca/wp-content/uploads/2010/10/POL3-March-2012-MB-Policies-Practices-in-the-Investigation-of-Missing-Persons-SuspectedMultiple-Homicides.pdf.

Canada's Missing. 2019. Background - 2019 Fast Fact Sheet. Available from: http://www.canadasmissing.ca/pubs/2019/index-eng.htm.

Cabarkapa, S., Sadhu, R., King, J., Dowling, N., Radhakrishnan, R., Akinbiyi, A., Srinivasaraju, R., \& Stevenson, D. 2020. Profiling absconders from public and private inpatient psychiatric units: A comparative analysis. Psychiatric Quarterly.

Carr, S. 2006. Evidence Summary: Absconded Patient: Clinical Information. Adelaide Australia: The Joanna Briggs Institute. Available from:

http://www.http://www.joannabriggs.edu.au/about/home.php.

Centre for Addiction and Mental Health [CAMH]. 2019. External review of the Centre for Addiction and Mental Health's Forensic Services: Passes and Privileges for Patients. Available from: https://assets.documentcloud.org/documents/6584472/External-Review-Report-forCAMH-Final-December.pdf.

Clark, J. 2012. 'You are going to drop the ball on this...': Using siblings' stories to inform better interprofessional practice when someone goes missing. Police Practice and Research, 13(1), 31-43.

Cohen, I M., Plecas, D., \& McCormick, A.V. 2009. A comparison of aboriginal and nonaboriginal missing persons in British Columbia where foul play has not been ruled out. Available from: https://www.ufv.ca/media/assets/ccjr/reports-andpublications/Missing_Aboriginal_Persons.pdf.

Cohen, I. M., McCormick, A.V., \& Plecas, D. 2008. A review of the nature and extent of uncleared missing persons cases in British Columbia. Available from: https://catalogue.libraries.coop/eg/opac/record/122742956? query=subject $\% 3$ AMissing\%20persons $\% 20$ Investigation $\% 20$ British $\% 20$ Columbia.

College of Policing. 2016. Risk Assessment. Available from:

https://www.app.college.police.uk/app-content/major-investigation-and-publicprotection/missing-persons/risk-assessment/\#classification-of-risk. 
Crammer, J.L. 1984. The special characteristics of suicide in hospital in-patients. British Journal of Psychiatry, 145, 460-463.

CQC. 2015. Right here. Right now. People's experiences of help, care and support during a mental health crisis. Available from:

https://www.cqc.org.uk/sites/default/files/20150630 righthere mhcrisiscare full.pdf.

Dickens, G L., \& Campbell, J. 2001. Absconding of patients from an independent UK psychiatric hospital: A 3-year restrospective analysis of events and characteristics of absconders. Journal of Psychiatric and Mental Health Nursing, 8(6), 543-550.

Duncan, S. 2020. Unsolvable? Assessing the accuracy of missing person case data. Available from: https://nsuworks.nova.edu/cgi/viewcontent.cgi? article $=1268 \&$ context $=$ fse etd/.

Emanuel, L.L. et al. 2013. Mental Health Care: Preventing and responding to absconding and missing patients. Available from:

https://www.patientsafetyinstitute.ca/en/education/PatientSafetyEducationProgram/Pati entSafetyEducationCurriculum/Documents/Module\%2013b\%20Absconding\%20and\%20 Missing\%20Patients.pdf.

Farragher, B., Gannon, M., \& Ahmad, I. 1996. Absent without leave: can we predict those who go AWOL? Irish Journal of Psychological Medicine, 13, 28-30.

Foy, S. 2016. A Profile of Missing Persons: Some Key Findings for Police Officers. In: Morewitz S., Sturdy Colls C. (eds) Handbook of Missing Persons. Springer.

Garside, R. 2015. The non-crisis of policing in England and Wales. June Centre for Crime and Justice Studies, Kinds College London. Available from:

http://www.crimeandjustice.org.uk/resources/non-crisis-policing-england-and-wales.

Gibson, V. 2019. Number of Patients who abscond from CAMH, other Canadian facilities varies year-by-year, data shows. Globe and Mail. Available from:

https://www.theglobeandmail.com/canada/article-number-of-patients-who-abscondfrom-camh-other-canadian-facilities/.

Government of Ontario., 2018. Missing Persons Act. Available from:

https://www.ontario.ca/laws/statute/18m03\#BK3.

Hausman, J. A. 1978. Specification tests in econometrics. Econometrica, 46, 12511271. 
Hausman, J. A., \& McFadden, D.L. 1984. Specification tests for the multinomial logit model. Econometrica, 52, 1219-1240.

Hayden, C., \& Shalev-Greene, K. 2018. The blue light social services? Responding to repeat reports to the police of people missing from institutional locations. Policing and Society, 28(1), 45-61.

Hayden, C., \& Goodship, J. 2015. Children reported 'missing' to the police: is it possible to 'risk assess' every incident? The British Journal of Social Work, 45(2), 440A56.

Houston, A. M., Brown, L.M., Rowe, M.A., \& Barnett, S.D. 2011. The informal caregivers' perception of wandering. American Journal of Alzheimers Disease \& Other Dementias, 2 6(8), 616-622.

Human Rights Watch. 2013. Those who take us away: Abusive policing and failures in protection of Indigenous women ad girls in Northern British Columbia, Canada. Available from: https://www.hrw.org/report/2013/02/13/those-who-take-usaway/abusive-policing-and-failures-protection-indigenous-women.

Hunt, I., et al. 2010. Suicide amongst psychiatric inpatients who abscond from the ward: A national clinical survey. BMC Psychiatry, 10(14), 1-6.

Independent Office for Police Conduct (IOPC). 2019. Learning the lessons: Missing People. Available from:

https://policeconduct.gov.uk/sites/default/files/Documents/Learningthelessons/36/Learn ingtheLessons Issue36 December 2019 single column.pdf.

Kiepal, L., Carrington, P.J., \& Dawson, M. 2012. Missing persons and social exclusion. Canadian Journal of Sociology / Cahiers Canadiens De Sociologie, 37(2), 137-168.

Kiernan, C., \& Henderson, M. 2002. Missing persons: Extending traditional policing boundaries to address a social issue. Available from: https://docplayer.net/22832431Missing-persons-extending-traditional-policing-boundaries-to-address-a-socialissue.html.

Kraemer, H.C., Kazdin, A.E., Offord, D.R, Kessley, R.C., Jensen, P.S., \& Kupfer, D.J. 1997. Coming to terms with the terms of risk. Archives of General Psychiatry, 54, 337343. 
Long, J. S., \& Freese, J. 2006. Regression Models for Categorical Dependent Variables Using Stata. STATA Corporation.

Meehan, T., Morrison. P., \& McDougall, S. 1999. Absconding behaviour: an exploratory investigation in an acute inpatient unit. Australian and New Zealand Journal of Psychiatry, 33, 533-537.

Millie, A. 2013. The policing task and the expansion (and contraction) of British policing. Criminology and Criminal Justice, 13(2), 143-160.

Muir-Cochrane, E., \& Mosel, K. 2008. Absconding: a review of the literature 19962008. International Journal of Mental Health Nursing, 17, 370-378.

Muir-Cochrane, E., Mosel, K., Gerace, A., Esterman, A., \& Bowers, L. 2010. The Profile of absconding psychiatric inpatients in Australia. Journal of Clinical Nursing, 20, 706713.

National Crime Agency (NCA)., 2019. Missing persons data report 2016/2017. Available from: https://www.missingpersons.police.uk/eng $\underline{b / r e s o u r c e s / d o w n l o a d s / m i s s i n g-p e r s o n s-s t a t i s t i c a l-b u l l e t i n s . ~}$

Niskanen, P., J. Lonnquist, K., Achte, R., \& Rinte-Manty. 1974. Suicides in Helsinki Psychiatry Hospitals in 1974-1972. Psychiatria Fernnica, 285-282.

Pages, K. P., Russo, J.E., Wingerson, D.K., Ries, R.K., Byrne, P.P., \& Cowley, D. S. 1998. Predictors and outcome of discharge against medical advice from the psychiatric units of a general hospital. Psychiatric Services, 49, 1187-1192.

Parr, H., \& Stevenson, O. 2013. Missing people, missing voices. Stories of missing experience. Glasgow, UK: The University of Glasgow.

Payne, M. 1995. Understanding 'going missing': Issues for social work and social services. The British Journal of Social Work, 25(3), 333-348.

Pfeifer, J. 2006. Missing persons in Saskatchewan: Police policy and practice. Available from:

https://publications.saskatchewan.ca/api/v1/products/76887/formats/86185/download.

Punch, M., \& Naylor, T. 1973. POLICE-SOCIAL SERVICE. New society, 24(554), 358361. 
Quinsey V.L., Coleman, G., Jones, B., \& Altrows, I.F. 1997. Proximal antecedents of eloping and reoffending among supervised mentally disordered offenders. Journal of Interpersonal Violence, 12, 794-813.

Rees, G., \& Lees, J. 2005. Still running II: findings from the second national survey of young runaways. Available from: https://www.childrenssociety.org.uk/what-wedo/resources-and-publications/publications-library/still-running-ii-findings-secondnational.

Royal Canadian Mounted Police (RCMP). 2019. Missing Persons Unit. Available from: http://www.rcmp-grc.gc.ca/ab/community-communaute/mis-dis/index-eng.htm.

Shah, A., \& Ganesvaran, T. 2000. Completed suicide among psychiatric in-patients with depression in an Australian mental hospital. International Journal of Methods in Psychiatric Research, 9, 25-31.

Shalev Greene, K., \& Pakes, F. 2013. The cost of missing person investigations: Implications for current debates. Policing: A Journal of Policy and Practice, 8(1) 27-34.

Stevenson, O., Parr, H., Woolnough, P., \& Fyfe, N. 2013. Geographies of missing people: Processes, experiences, responses. Glasgow: The University of Glasgow.

Swanton, B., \& Wilson, P. 1989. Research brief: Missing persons, trends and issues in crime and criminal justice. Available from: https://aic.gov.au/publications/tandi/tandi17. Tammelleo, A. D. 1999. Mental patient escapes through hole in fence. Hospital Law's Regan Report, 39(9), 4.

Tarling, R., \& Burrows, J. 2004. The nature and outcome of going missing: the challenge of developing effective risk assessment procedures. International Journal of Police Science \& Management, 6(1), 16-26.

Taylor, C., Woolnough, P., \& Dickens, G. 2019. Adult missing persons: A concept analysis. Psychology, Crime \& Law, 25(4), 396-419.

Welch, E. 2012. Practices and Procedures in The Investigation of Missing Persons Across Canada: 1997 To Present. Available from: http://www.missingwomeninquiry.ca/wp-content/uploads/2010/10/RESE-2-March-2012EW-Practices-Procedures-in-Investigation-of-MP-Across-Canada.pdf. 
Wilkie, T., Penney, S.R., Fernane, S., \& Simpson, A.I.F. 2014. Characteristics and motivations of absconders from forensic mental health services: A case-control study. BMC Psychiatry, 14, 14-91.

Wilson, C. 2019. CAMH review prompted by missing patients is now complete. Available from: https://toronto.ctvnews.ca/camh-review-prompted-by-missing-patientsis-now-complete-1.4734925.

Woolnough, P., Alys, L., \& Pakes, F. 2016. Mental health issues and missing adults. In K. Shalev Green \& L. Alys (Eds.), Missing persons: A handbook of research, Routledge.

\section{Footnotes}

1. As an example of why these classifications can be important, a recent study by Huey et al. (2020) found that 'habitual/chronic' missing person cases ranged from three previous missing person reports to 144 prior reports. $\_$

2. 'Highest' risk means that these cases represent the greatest concern, such as increased chances of harm and/or the missing episode is an out-of-character behaviour. Police risk assessment features several risk factors that are considered when determining such risk and urgency levels (see, for example, British Columbia 2018). 